in Egypt has been extraordinary. There has been much rain and very little khamseen, and now there is a brisk north wind blowing, which generally follows the dust wind. Hence many weather-wise people say that the khamseen is over; if so, of course, all the better. On the other hand, to-night from our sandbank we have witnessed a sunset rendered transcendentally beautiful by clouds over fully one-half of the sky. It is possible therefore that if the present weather continues, the sky will not be quite so free from vapour as it is generally in Upper Egypt. To avoid the khamseen, General Stone, who has had the region reconnoitred, has suggested to the English party to occupy an eminence to the northwest of Akmin, a village a little higher up the river than Sohag.

\section{Near Sohag, Sunday}

I had got so far at I I last night, when the time came for closing the mail bag, although we were fast aground, and apparently with less chance than ever of getting off. There were two mail bags, however, made up after all, for the service is so interfered with higher up the Nile that I am still in time on Sunday evening to send a letter which ought to catch the next Brindisi mail, though whether it does or nor is very doubtful, for we have been aground again twice to-day.

So, as we have at last arrived at our station, I will endeavour to give an idea of the proposed arrangements. In the first place, we have found the steamer on which the various parties are to live as the guests of the Khedive moored close to the shore, at a point where it trends north and south, or very nearly so, about half a mile below Sohag. This position, which has been selected by the French party - the first to arrive-is a very admirable one for two reasons. First, the constant wind during the last week has been from the north, and by keeping a staff of people watering the foreshore of the Nile, all dust is obviated. To the north of the place of observation trees, and what looks like grass from a distance, grow close to the margin of the river; so that the dust can only be of nearly local origin; while a long stretch of sandbank to the north, running east and west, is far enough away to deposit its sand in the Nile before it can reach us.

Secondly, the khamseen, if khamseen there is to be, will have to travel a mile and a half along the Nile before it can enter the observatories; and it is thought this amount of water surface will have an important effect in reducing the amount of sand in the air, even in its case also. Nous verrons. These considerations have induced the Inglish party to take up ground close to the boat and their French confrères. The hills which look so tempting in the mass are simply impossible as places of observation. With the means at command here it would take a week to get the instruments up, much more in position; while at Akmim, which is only two or three miles away, there does not seem to be any spot more favourable, taking everything into consideration, than the one here.

At five o'clock to-morrow, then, the work will begin, and the next week will be a busy one, for in spite of the fresh breeze and the clouds-for there are very distinct clouds to-day--work on the sand becomes very oppressive in the middle of the day, and there are heavy weights to move, which the observers must move themselves. The scene from the ship is already interesting. To the north two tents and various shelters, to the south one tent. These will increase to six to-morrow. Here and there groups, looking down the bank, stealthily from between the trees. There is a pretty thick grove of acacia trees, which shelter us somewhat from the rays of the setting sun, still fierce in this latitude. Here and there, skirting the grove, a sentinel with fixed bayonet keeping guard. At the extreme soutb, tents for the military, and a long line of piled arms.

Across the water the scene is novel and beautiful in the extreme. The main Nile, in which the bat is anchored, is here about half a mile wide, but there is an island about two miles long, and a wide stretch of water beyond that. This island forms, with the river, the foreground of the landscape. With an opera-glass we can see the Fellaheen cultivating the ground almost to the water's edge in places, and looking after their crops of maize or their flocks of goats. Here comes a veiled Rachel to the sacred river to fetch water for a house in an indistinct flat-topped village, sheltered in a large group of beautiful palm trees. The arm of the river beyond the island we cannot see, but a background is not lacking. A long line of mountains, we may almost call them, full of geological tracery, are now, as I write, almost blood-red in the light of the setting sun, and are surmounted by that grey purple one always sees to such advantage in Eastern lands-both grey and purple haze in a few hours to give way to the silver dawning of the moon, now terribly dwindling in her visible surface, and reminding the astronomers of the coming seventy seconds in a most forcible manner.

The proceedings at the end of the first day on which the English and French parties found themselies together as guests of the Egyptian Government naturally included some toasts - that of his Highness the Khedive, proposed by M. Trépied, and that of the English and French nations, proposed by Moktah Bey, and responded to by Mr. Norman Lockyer. The arrangements on board are as perfect as those made at the various stations on shore, and one's national pride is a little touched at the idea of what the Government reception would be of a party of Egyptian astronomers coming to England to observe an eclipze of the sun.

\section{ANEMOMETRICAL OBSERVATIONS ON BOARD SHIP}

I $\mathrm{T}$ is known that the determination of the velocity of the wind in the ocean has always been one of the desiderata of meteorological observations. Maury devoted much attention to this subject, and to determine, at least approximately, the velocity of trade-winds, he was compelled to work on a very unsafe basis-the velocity of ships during different parts of the year-and to put aside all observations made in accordance with the scale of Beaufort as unreliable. But it is obvious that the velocity of a ship depends on so many circumstances quite independent of the wind itself (such as the shape of the ship, the surface of its sails, the disposal of the cargo, and so on), that its velocity is kut a very imperfect means of measuring the velocity of wind. Besides, the relation which exists between the force of the wind and the velocity of a ship, under different angles between the direction of both, is a new source of error, as this relation has not yet been established with accuracy, and can be established only by means of anemometric measurements. The necessity of trustworthy measurements of the velocity of wind at sea was so well understood in England that the Royal Society and the British Association established in 1859 two anemometers-one on the Bermuda Islands, and the other at Halifax. But it is known that the force of the wind is usually lessened on continents and islands.

Therefore it was absolutely necessary to make anemometrical observations on board ships, and a few attempts had already been made in this direction. Prof. Piazzi Smith invented an anemometer which might be established on board a ship, and which merited the bighest eulogy from Maury, but Lieut. Domojirov does not know if any observations were made with it. Emil Bessel, during the Arctic expedition of the Polaris, made a series of observations with an anemometer on board his ship, but he does not explain, neither the methods of observation, nor the corrections he applied to his measurements. In

${ }^{1}$ A. Domojirov, in the Izvestia of the Russian Geographical Society, vol. $x$ viii. 1882 , fasc. $x$. 
1879 Col. Rykatchoff, of the St. Petersburg Central Physical Observatory, established, on board the Nayezdnik. an anemometer of his own construction, which was observed during the ocean cruise of the clipper; and the schooner Nordenskjöld, which unhappily was lost in 1879 at Yesso Island, had also an anemometer, which was taken afterwards on board the Russian clipper Djighit by $M$. Domojirov. The observations on board of the Djighit were carried on with this anemometer (of Casella) put in such an apparatus (like that of the lamps on board of ships), as always maintained it in a vertical position, even during the heaviest seas, when the ship oscillated for $30^{\circ}$ on one side, and $35^{\circ}$ on the other. The apparatus was put on a 16 -foot-long pole, which was pushed out for each observation on the wind-side of the ship, from the boat, and thus exposed to the full force of the wind for ten minutes. The height of the instrument above the sea was 26 feet. The direction of wind was determinated by means of a vane, and its true direction computed from the apparent one, on the principle of the parallelogram of forces, by taking into account the velocity of the ship. When the angle between the direction of the wind and the direction in which the ship goes is known, as well as the seeming velocity of wind (measured by the anemometer), and the velocity of the ship, the true velocity of wind is easily determined by means of simple computations, or of the tables published for that purpose by M. Rykatchoff (Russian Marine Review, February, 1880). A series of experiments having been made for ascertaining in how far the calculated figures agree with the true ones, M. Domojirov arrives at the conclusion that these figures are quite reliable; determination having been made during the progress of the ship, she was immediately stopped, and the determination made anew, both results always being quite identical. But the measurements from the side-boat are very tedious and even dangerous during heavy seas, and each observation occupies no less than three men for about twenty minutes. Therefore M. Domojirov proposes to apply electricity to register the rate of the anemometer.

The observations on board the Djighit were made five and six times per day from March 23 to May 30 , and the complete results, with all elements for calculations, are published in the papers of M. Domojirov. The northeastern trade-wind, observed on the passage from Japan to the Sandwich Islands and back, had a very regular force of from 5 to 9 metres per second; the south-eastern trade-wind experienced on the passage from the Sunda Islands to the Seyschels, had a velocity of 4 to 9 metres per second, and the south-western winds on the passage from Port Victoria to Aden, had velocities from I2 to I5 metres per second.

It would hardly be necessary to insist on the importance of such observations for meteorology, as well as for practical purposes, and we hope that soon the still prevailing prejudices as to the possibility of anemometrical observations on board ships having disappeared, and more convenient methods of observaticn having been devised, the anemometer will become on board ships as necessary an instrument as the $\log$ and barometer.

P. K.

\section{INSTANTANEOUS PHOTOGRAPHY OF BIRDS IN FLIGHT}

$\mathrm{P}$

ROF. E. J. MAREY has lately published in the pages of our contemporary, La Nature, an article on a "photographic gun," the illustrations to which, with a somewhat shortened account of the process, we are enabled, through the courtesy of the editor of La Nature, to present to our readers. M. Marey's researches on animal locomotion are well known; his experiments carried on by the graphic method were productive of most valuable results, and they corrected and explained many debated points in animal mechanics; but having seen some of the results obtained by Mr. Muybridge, at San Francisco, with photographic pictures taken during an exposure of the 1-500th of a second, he was very desirous to have the same process adapted, so as to admit of its being applied to the taking of birds flying. In September, 1881, on a visit of $\mathrm{Mr}$. Muybridge to Paris, he brought with him some photographs of birds taken on the wing, but these unlike the invaluable series taken by the same gentleman of horses and men, were not the representation of a series of continuous attitudes, but rather represented the bird in the position it happened to be in at a moment of time ; whereas, to explain the fall and rise of the wings and the positions of

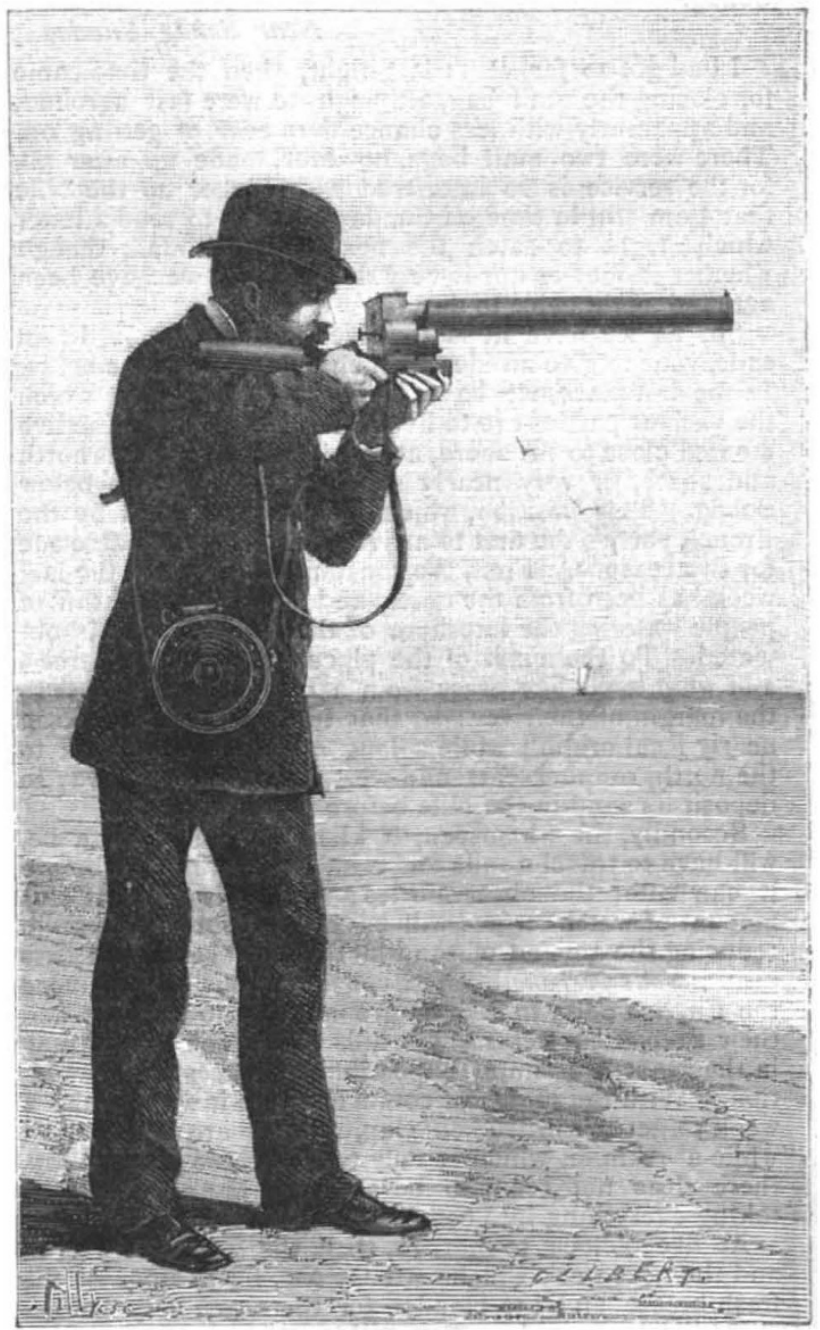

FIG. I.-The Photographic Gun.

the body, it was, above all things, important to have a series of rapid photographs taken of the same bird over a period during which the whole mechanism was in action, so as to allow of the movements to be afterwards studied at leisure. After deliberating over this subject during the last winter, at last the idea of a photographic gun occurred to him; but the immense quickness with which the movements should succeed one another, in order to bring a series of sensitive surfaces across the lens, at first presented great difficulties in the constructing of the machine. It was necessary to have images taken successively ten or twelve times in one second, in order to 